\title{
Vulture updates - October 2016 - Around the World of Vultures \& VSG activities
}

Updates include the latest on the CMS Multi-Species Action plan, the upcoming Africa meeting, further poisoning incidents, NSAIDs in Asia and elsewhere.

The CMS Africa-Eurasian Vulture Multi-species Action Plan (MsAP): The process of developing the MsAP formally began in August with the appointment of an overarching coordinator, Andre Botha, and three regional coordinators: Masumi Gudka (Africa), Jovan Andevski (Europe \& central Asia) \& Chris Bowden (Asia). So you will realise that as well as our VSG hats, three of us also now wear CMS hats for the coming 18 months up to delivery! Three regional workshops are planned for the last quarter of 2016 in Senegal (PAVS2), Spain and India which will produce conservation strategies for each region. These will be combined into an overarching MsAP at a fourth workshop in February 2017 with the final document due to be submitted to the CMS Secretariat in May 2017. This will be distributed to all CMS signatories for consideration and ratification at the $12^{\text {th }}$ Conference of the Parties in October 2017. Vulture
MsAP questionnaires have been circulated to experts and officials in all three regions, and so this is an important opportunity for many of the VSG membership to actively contribute in this way and/or by attending the meetings.

\section{At the IUCN World Conservation}

Congress held in Hawaii, four key motions relevant to vultures were approved: One highlighting the poisons issue and diclofenac for African-Eurasian Vultures, one specifically combating illegal wildlife poisoning, a third related to preventing bird electrocution and collisions with power infrastructure, and finally one on phasing-out lead ammunition in hunting. VSG, BirdLife and CMS hosted an African-Eurasian vulture pavilion event to bring together vulture experts and concerned individuals from all regions and IUCN Pakistan held another vulture forum there further endorsing similar messages.

IVAD 2016 - over 110 registered events and we know that many more were not registered, and also that many of these successfully raised significant funds and awareness for 
vultures. One year we should fully document the full extent of these activities, but it's very clear these events are having important impact and well done to all of you who held events. An online quiz in Africa was a novel success there.

African roundup: The $2^{\text {nd }}$ PanAfrican Vulture Summit was integrated with Africa's regional contribution to the CMS Vulture MsAP and was held as part of the Pan-Africa Ornithological Congress in Dakar, Senegal 17-21 October 2016.

Policy and Advocacy: Nigerian Federal Minister of State (Environment), Nigeria highlighted the importance of vultures at the African Ministerial Conference on the Environment in August noting the serious threat their loss could be for national economies. African governments made a commitment towards addressing illegal wildlife trade in Africa by agreeing on an implementation road map for the African Strategy on Combating Illegal Exploitation and Illegal Trade in Wild Fauna and Flora in Africa. At another event, Healthy Vultures, Healthy People were linked during the United Nations Environment Assembly 2 in Nairobi. A high-level panel and speakers discussed the important role vultures play in the ecosystem and in delivering human health benefits. The Commissioner of the African Union pledged support. The National Agro-chemical Act review in Botswana successfully placed emphasis on creating stricter regulation and monitoring from entry up-to disposal points of highly toxic agro-chemicals including Carbofuran, recommending the removal of such chemicals from the market to be substituted by less toxic ones. BirdLife Botswana has been particularly active in pushing for this, along with other measures including stiffer penalties for misuse of chemicals to kill wildlife. A BirdLife brochure highlighting the vulture crisis in Africa was produced and will soon also be available in French. BirdLife Nairobi embarked on a gruelling quest to climb $\mathrm{Mt}$ Kenya to raise awareness of the plight of African vultures. Ghana Wildlife Society gained national TV profile for Hooded Vultures. An hour-long vulture documentary filmed in Kenya, Vultures in Crisis was screened on national Kenya TV.

Actions and new projects: Poisoning intervention training was completed since February for 534 people in South Africa, Zambia, 
Mozambique and Namibia. An example of the benefit of this training was the response from staff of when a poisoned elephant carcass was located in the South Luangwa National Park and due to their rapid action, a single lion was lost, five others successfully treated and no vultures lost thanks to effective decontamination. To address knowledge gaps in vulture occurrence and breeding activity, road transects were conducted as part of the VSG African Vulture Project. Surveys have also been carried out in Zambia, Mozambique, Kenya and Zimbabwe since July and more are planned over the next 2 years with all data submitted to the African Raptor Databank. BirdWatch Zambia is developing a small project to pilot Vulture Safe Zones on private farms that have been recorded to host several hundred vultures. The project goal is to develop and sustain partnerships with farm owners to ensure the safety and survival of vultures on their land as well as raise awareness and appreciation for the species status and importance to human, livestock and general environmental health. Nature Kenya, The Peregrine Fund and other stakeholders developed a draft poisoning response protocol for Kenya to help local authorities with protocols at a poisoning crime scene i.e. contaminated carcasses and surroundings, to obtain suitable evidence for convicting offenders. Another training workshop on Pesticide Crime and Wildlife Poisoning Investigations took place in Hwange National Park (Zimbabwe) in July as part of a project on Saving Africa's Vultures involving government department and NGO staff.

\section{Major incidents/mortalities since March}

- N. Botswana: 150 vultures (two incidents) - by poisoned cattle and hippo in June 2016.

- Zambia: 105 Vultures (4 species) poisoned at poached elephant near South Luangwa NP.

- $\quad$ Tanzania: 56 vultures, 2 Bateleur \& a Tawny Eagle poisoned on a poisoned lion that was targeted due to livestock predation near Ruaha NP.

Research: A study involving GPSGSM tagging of Hooded Vultures in the Masai Mara to will show breeding locations in relation to potentially disturbing tourism facilities. Caroline Howes completed her University of the Witswatersrand project on power-line risk to Cape (Gyps coprotheres) and White- 
backed (G. africanus) vultures in southern Africa. Maggie Hirschauer completed her Master's research at Rhodes University on effect of age at release on survival of captive-bred Cape Vultures. Morgan Pfeiffer completed her $\mathrm{PhD}$ research at the Unversity of KwaZulu-Natal on ecology and conservation of the Cape Vulture in the Eastern Cape Province, South Africa. A two-week survey project for vultures and other raptors was conducted in far northern Kenya during May 2016. Hooded Vultures satellite-tagged beginning in 2013 in association with Hawk Mountain and its many collaborators field efforts are still active in Ethiopia (2 individuals), The Gambia (3), and South Africa (8). All of the birds appear to be non-migratory or, in a few instances, seasonally nomadic.

Breeding: 2016 has been the most productive year to date for VulPro's captive breeding programme with 8 healthy Cape Vulture chicks being cared for by genetic (2) or foster (6) parents. There will also be a raptor husbandry and incubation workshop held there (in NWP, South Africa) 911 January 2017.

Asian roundup: The Indian Federal Environment Minister was party to the pilot release in June of two Himalayan Vultures as a test of the methodology for the more endangered species at the Haryana release site. Although Government tagging permissions were not granted in time, this still proved a useful exercise and should help pave the way for future releases of tagged vultures in future - assuming further surveys of diclofenac indicate that levels are sufficiently low within a $100 \mathrm{~km}$ radius. Meanwhile the BNHS breeding centres produced 60 fledglings of the three critically endangered species this year in India, and the Pakistan centre at Changa Manga produced its first two offspring. As well as the releases now being planned in India, government approval was also given for the plan to release the first White-rumped Vultures in Nepal, which could also take place in 2017. There was a key meeting convened by IUCN Bangladesh with the Bangladesh Government in May in Dakar to advance the process of banning ketoprofen, which has become popular with vets but is known to be toxic to vultures. There was also a regional vulture meeting in May in Karachi, called by IUCN Pakistan, which successfully engaged senior government in the discussions to ban toxic NSAIDs, 
and proceedings should become available from this. In Cambodia, the national vulture action plan was finalised in March. The sixth annual SAVE meeting was held 27-28 November in Mumbai and had a strong emphasis on drug regulation and the plans for safety-testing of a range of NSAIDs.

Middle East: An update from Oman: Four GPS-GSM transmitters fitted to sub-adult Egyptian Vultures in the last two years. Two have died: One from electrocution, another of unknown causes, though electrocution, poisoning or shooting are possibilities. A third bird disappeared, and is probably dead. The movements of those birds have generated considerable interest and new information is still being added. A short film has been produced about vultures using rubbish dumps in Oman, and is currently in the review stage. A 2016 paper in Sandgrouse 38 reports numbers of vultures using the Muscat municipal dump. During winter, numbers of Egyptian Vultures can exceed 400 individuals. Lappet-faced Vultures, Steppe Eagles, Spotted Eagles and Eastern Imperial Eagles also feed at the rubbish dump.
Americas roundup: South America: Andean Condors from all over Argentina, and elsewhere in South America, have been tested for lead contamination. Alarming results are emerging and suggest that Andean Condors may be similarly threatened by lead poisoning to California Condors. Publications should appear shortly on this. Another emerging threat for Andean Condors, currently under closer investigation throughout the range, is the negative perception by humans in rural areas, and potential ways to address this. American Black Vultures have been captured in Argentine Patagonia examining their body condition, blood biochemistry, toxicology and bacteriology to check how for any adverse effects relating to frequenting of rubbish dumps.

North America: Five American Black Vultures have been fitted with GPS or GSM-GPs satellite tracking devices in eastern Pennsylvania, US, near Hawk Mountain Sanctuary. The first was fitted in July 2014, the most recent one in July 2016. The birds appear to be non-migratory, although several changed their home ranges in summer versus winter while retaining a single roost site year-round. Additional deployments are planned for this population, 
which appears to be growing. Hawk Mountain Sanctuary continues to follow the movements of 18 Turkey Vultures, the first of which was tagged in June 2007 (and is now wearing its second unit after being retagged two years ago) and the most recent in January 2016. The birds that were tagged on central Saskatchewan continue to overwinter in Colombia and Venezuela. Those tagged in Pennsylvania overwinter both in Pennsylvania and in the south-eastern US, and those tagged in Arizona, overwinter both in Arizona and Mexico, and in Central
America as far south as central Panama.

Note no California Condor updates were received, nor from the European Regional chair - see next issue!

Regional Chairs and Administrative Assistant of VSG. We warmly welcome the appointment of Sergio Lambertucci as regional chair for Latin America, and Lesley Jerome (of the Hawk Conservancy Trust) as VSG admin assistant to the Co-chairs.

Chris Bowden

\section{IUCN}

Andre Botha

\section{Co-chairs: Vulture Specialist Group, IUCN Species Survival Commission}

African Regional Co-chairs: Darcy Ogada, Masumi Gudka

European Regional Co-chair: Jose Tavares

Latin Americas Co-chair : Sergio Lambertucci

Additional contributions: Lesley Jerome (VSG Admin assistant), Mike McGrady, Keith Bildstein, Sharif Jbour, Kerri Wolter, Scott Tidmus. 